Published: Physical Chemistry Chemical Physics. 2013, 15: 18671-18677. doi:10.1039/C3CP53282H

\title{
CO Oxidation on Stepped-Pt(111) under Electrochemical Conditions: Insights from Theory and Experiment
}

\author{
C. Busó-Rogero, E. Herrero* \\ Instituto Universitario de Electroquímica, Universidad de Alicante, \\ Apdo. 99, E-03080 Alicante, Spain \\ J. Bandlow, A. Comas-Vives, and Timo Jacob* \\ Institut für Elektrochemie, Universität Ulm, \\ Albert-Einstein-Allee 47, D-89069 Ulm, Germany
}

\begin{abstract}
The co-adsorption of $\mathrm{CO}$ and $\mathrm{OH}$ on two Pt stepped surfaces vicinal to the (111) orientation has been evaluated by means of density functional theory (DFT) calculations. Focusing on $\operatorname{Pt}(533)$ and $\operatorname{Pt}(221)$, which contain (100) and (111)-steps, respectively, we find that (111)-steps are more reactive towards CO oxidation than surfaces containing (100)-steps. The DFT results are compared with electrochemical experiments on the $\mathrm{CO}$ adsorption and oxidation on these vicinal surfaces.
\end{abstract}

Keywords: CO oxidation, CO/OH Co-adsorption, Pt-stepped surfaces, Density Functional Theory

*corresponding authors: herrero@ua.es, timo.jacob@uni-ulm.de

\section{Introduction}

Improving the catalytic performance of electrochemical reactions and designing new and more efficient catalysts requires a deep knowledge of how and where the reaction is taking place on a given electrode. To gain such knowledge, the reaction must be studied under very controlled conditions, so that the mechanism and the effects of different environmental parameters can be untangled. Since the most important electrochemical reactions are structure-sensitive, many of these model studies involve the use of single crystal electrodes, allowing for a direct comparison to theoretical studies to unravel the reactivity of different surface sites. This finally helps understanding the catalysts' behavior in practical applications.

Of particular importance are stepped surfaces, as they combine terraces of a given orientation with monoatomic-high steps. The steps are composed of atoms with low coordination, which significantly affects their reactivities. Furthermore, in most cases these sites show almost identical behavior as low-coordinated atoms that are present on nanoparticles used in practical electrodes - for particle sizes beyond the quantum-size region. It has been shown that steps often have an important effect on the reactivity of surfaces. For instance, (111)-steps on vicinal $\mathrm{Pt}(111)$ surfaces are able to break the $\mathrm{C}-\mathrm{C}$ bond in the ethanol oxidation reaction, so that the final product is $\mathrm{CO}_{2}$ and not acetic acid [1-3]; or that $\mathrm{CO}$ formation from formic acid only takes place on (111)-steps [4,5].

Among the most studied reactions in electrochemistry, $\mathrm{CO}$ adsorption and oxidation occupies a prominent place. Understanding this reaction is very important for fundamental electrochemistry but also for fuel cell research, since $\mathrm{CO}$ is involved either as a poison or as an intermediate in the anode reactions. In this way, traces of $\mathrm{CO}$ are present in hydrogen steams when being obtained by reforming hydrocarbons. Further, $\mathrm{CO}$ is an intermediate in the main or side paths in the oxidation mechanism of formic acid, methanol and ethanol [6,7]. Although our knowledge of the $\mathrm{CO}$ oxidation mechanism has improved over the last years, there are still many unsolved issues.

The oxidation kinetics of adsorbed $\mathrm{CO}$ on Pt single crystal-electrodes has been extensively studied both in the absence [8-18] and in the presence of dissolved $\mathrm{CO}$ in acidic solutions [19-22]. These studies have revealed that the CO oxidation on $\operatorname{Pt}(111)$ and vicinal electrodes takes place according to the mean field Langmuir-Hinselwood $(\mathrm{L}-\mathrm{H})$ mechanism $[10,11,14,16]$, in which adsorbed $\mathrm{CO}$ reacts with an adsorbed $\mathrm{OH}$ species originating from waters' dissociative adsorption. Since the oxidation process takes place at very localized sites where $\mathrm{OH}_{\text {ads }}$ and $\mathrm{CO}_{\text {ads }}$ species can interact, the mean field $\mathrm{L}-\mathrm{H}$-type mechanism is fulfilled only if $\mathrm{CO}$ diffusion on the surface is fast [23]. Ab initio results for the $\mathrm{CO}$ electro-oxidation on $\mathrm{Pt}(111)$ have also proposed that adsorbed $\mathrm{OH}$ oxidizes $\mathrm{CO}$ molecules [24-26].

It has also been observed that steps play a critical role in oxidation processes. An extrapolation of the rate constants for the $\mathrm{CO}_{\text {ads }}$ oxidation obtained with $\mathrm{Pt}(111)$ vicinal electrodes to the "ideal" (defect-free) $\operatorname{Pt}(111)$ electrode indicates that the oxidation on real Pt electrodes is expected to take place almost exclusively at defect (or lowcoordinated) sites [16]. Further, studies in basic solutions indicate that $\mathrm{CO}$ mobility under those conditions must be slow. Whereas in acidic media, only one oxidation peak is found in the oxidation voltammogram, two or even three peaks appear in basic solutions [27], depending on the 
different type of sites present on the surface. Thus, the peak corresponding to $\mathrm{CO}$ oxidation on (111)-steps in alkaline media appears at lower potentials than on (100)-steps or on (111) terraces [28,29]. This clearly indicates that the reactivity of steps is indeed different depending on their symmetry. Here, adsorbed $\mathrm{OH}$ should play a very significant role on the overall process, since $\mathrm{CO}$ oxidation requires the presence of $\mathrm{OH}$ on the surface. Regarding this issue, UHV experiments have shown that the properties and adsorption energies of $\mathrm{OH} / \mathrm{O}$ depends on the step symmetry [30-33].

In this manuscript, our aim is to study the process of $\mathrm{OH}$ and $\mathrm{CO}$ adsorption on stepped $\mathrm{Pt}$ surfaces vicinal to the (111) orientation by means of density functional theory (DFT) and comparing the energetics to experimental studies on the $\mathrm{CO}$ electro-oxidation process on $\mathrm{Pt}$ stepped electrodes.

\section{Methods: DFT Calculations and Experimental Details}

DFT energies for the different Pt surfaces were evaluated using the SeqQuest code [34] with localized basis sets represented by a linear combination of optimized " double- $\zeta$ plus polarization" contracted Gaussian functions and normconserving pseudopotentials, including nonlinear core corrections. The PBE-GGA functional was employed to approximate exchange and correlation energies. The $\operatorname{Pt}(111)$ terrace as well as both step edges were modeled by unsymmetric seven-layer slabs. Integrations in reciprocal space were performed on $10 \times 10$ (terraces) and $5 \times 10$ (steps) Monkhorst-Pack $\boldsymbol{k}$-point meshes. As models for stepped $\operatorname{Pt}(111)$ we used $\operatorname{Pt}[4(111) \times(100)]$ and $\operatorname{Pt}[4(111) \times(111)]$ surfaces, thus for both surfaces steps are separated by fouratom wide terraces, corresponding to $\operatorname{Pt}(533)$ and $\operatorname{Pt}(221)$ vicinal surfaces, respectively. With both surfaces we concentrated on the low-coverage limit by using surface unit cell with two step-edge atoms (two times the unit cells shown in Fig. 1). For the separate adsorption of $\mathrm{CO}$ (or $\mathrm{OH}$ ) placing one adsorbate in the unit cell leads to a coverage of 0.50 SML (SML - step-edge monolayers) or $\sim 0.125 \mathrm{ML}$ (per entire unitcell). Consequently, coadsorption of $\mathrm{CO}+\mathrm{OH}$ resulted in coverages of twice these values. We also investigated higher coverages, which, however, showed strong adsorbate-adsorbate repulsion. Binding energies of $\mathrm{CO}$ and $\mathrm{OH}$ were referenced to the molecules in gas-phase, where positive values indicate strong binding.

The protocol and reagents for the electrochemical experiments have already been described in Ref. [35]. In summary, single crystal electrodes were flame-annealed, cooled down in a $\mathrm{H}_{2}+\mathrm{Ar}$ atmosphere and protected by a water film [36]. It has been shown that this treatment leads to surfaces with topographies close to the nominal [37].

\section{Results and Discussion}

\subsection{CO adsorption on stepped $\operatorname{Pt}(111)$ surfaces.}

The presence of steps on the (111) terrace modifies the surface stability and its properties, such as the work function or the potential of zero charge, which was found to be directly proportional to the step density [38-40]. This linear relationship normally breaks up for surfaces with narrow terraces [40], where. the perturbation generated by the presence of steps extends over the whole terrace, and step-step interactions may appear. Thus, the behavior of these surfaces no longer can be considered as the sum of step and terrace contributions. Therefore, we always have to compare with the behavior of the perfect (111) surfaces without steps. Therefore, $\mathrm{CO}$ adsorption was studied on planar $\operatorname{Pt}(111)$ and both types of stepped surfaces, i.e. (100) and (111)-steps. Table 1 shows the calculated CO adsorption energies on the different sites of the (111) terrace. Four different adsorption geometries have been considered: atop, bridge, fcc, and hcp sites. We find very similar adsorption energies at all four sites. Indeed, $\mathrm{CO}$ adsorption on Pt surfaces is indeed a non-trivial system to be calculated with DFT in general as the approach usually tends to overestimate the 3-fold hollow sites over atop sites, which in low temperature experiments were found to be preferred. As our aim is to investigate the co-adsorption of $\mathrm{CO}$ and $\mathrm{OH}$, here we point the reader to the extensive discussions about the so-called "CO/Pt(111) puzzle" [41-53].

Our results indicate that at low coverages the $\mathrm{CO}$ adsorption on the terrace has no preferential adsorption site (due to similar binding energies), which is comparable to the findings already reported in literature [41-53]. However, the exact geometry of the adsorption certainly depends on various additional factors, such as coverage and lateral interactions between adsorbed $\mathrm{CO}$ molecules.

In electrochemical environments, $\mathrm{CO}$ forms different structures on the $\operatorname{Pt}(111)$ electrodes [54], which usually combines $\mathrm{CO}$ at various surface sites (e.g. atop, bridge, multi-bonded positions, and even combinations of these [54]), providing a clear indication that the adsorption energies are indeed very similar at the different surface sites. In order to cover the effects induced by the electrode potential on the systems, different groups performed DFT studies on the $\mathrm{CO}$ adsorption on $\mathrm{Pt}(111)$ under the influence of a constant electric field [55-57], concluding that the preferred $\mathrm{CO}$ adsorption position changes from atop to fcc under decreasing external electric field $[55,56]$.

For stepped surfaces, various possible adsorption sites above and below the step-edge have been considered (see Fig. 1): atop sites (T1 to T4 sites), two different bridge geometries, corresponding to the situations in which the two atoms are in the same atomic row (A sites) or in different ones (B sites), and the fcc and hcp geometries ( $\mathrm{F}$ and $\mathrm{H}$ sites, respectively). Additionally, other adsorption geometries have been studied when the adsorbates are located on sites defined by the atoms on the step edge and the first row of atoms of the $\operatorname{Pt}(111)$ terrace underneath. For the (100)-step, we additionally evaluated $\mathrm{StBr}, \mathrm{StCe}$ and $\mathrm{H}-1$ sites, depending on the adsorbate position, namely on a bridge position, on the center of the (100) step-edge or on an hcp site, respectively. For the (111)-steps the corresponding F-1 site was evaluated, which corresponds to the fcc site formed 
between one atom of the step-edge and two Pt atoms of the $\mathrm{Pt}(111)$ terrace underneath.

All binding energies are summarized in Table 2 and Table 3. Missing values indicate unstable surface sites, since the adsorbed species relaxed during the optimization to other positions. The obtained adsorption energies clearly show that binding of $\mathrm{CO}$ on the step edge is favored with respect to the terrace sites by roughly $0.3-0.4 \mathrm{eV}$. Although the qualitative picture for the two stepped surfaces is similar, quantitative differences are observed. Thus, for the (100)step, the most favorable adsorption site on the step corresponds to a bridge position between two Pt atoms on the step-edge (Fig. 2B) although the atop T1 site is similar in energy in agreement with previous DFT results $[41,58]$. On the (111)-step CO binds to only one Pt atom (Fig. 2A) as already reported by previous $a b$ initio calculations $[41,58,59,60]$. This latter site correspond to a geometry in which the $\mathrm{C}-\mathrm{O}$ bond is normal not to the (111)- but the (221)-plane.

The results presented here are in good agreement with experimental findings obtained for the Pt electrodes vicinal to the (111) plane. In acid media, it has been proposed that the CO mobility is very high [10]. Thus, CO should always occupy the energetically most favorable sites. For stepped electrodes vicinal to the (111) plane, it is possible to identify the adsorption site of a species using voltammetry. Hydrogen adsorption-desorption processes on step sites give a characteristic peak at 0.27 and $0.13 \mathrm{~V}$ for the (100)- and (111)-steps, respectively. For partial CO coverages, even at very low values, the characteristic peak corresponding to the step sites disappears, indicating that $\mathrm{CO}$ preferentially occupies step sites. This effect can be observed in Fig. 3, where a partial $\mathrm{CO}$ stripping experiment has been carried out. By choosing the appropriate upper potential limit, $\mathrm{CO}$ is stripped slowly from the surface. As can be seen, the peak corresponding to the adsorption of hydrogen on the step sites is only recovered in the final stages of the oxidation, that is, when the $\mathrm{CO}$ coverage is very low. Additionally, it can be observed that the hydrogen adsorption peak on the (100)- and (111)-steps shifts towards positive potentials in the latter stages of the stripping process. This shift is very similar to that observed for other species adsorbed in the upper part of the step, such as selenium [61]. The change in the peak potential clearly indicates a change in adsorption energy due to either a modification in the energetics of the step or lateral interactions.

The adsorption geometries have also been determined using Fourier-Transformed InfraredSpectroscopy (FTIR), both in acid and alkaline media $[62,63]$, which indicates that this adsorption geometry is not strongly affected by the electrode potential. The adsorption geometry on the step has been obtained by comparing the FTIR spectra of CO on the stepped surface before and after blocking the step site with Bi. From the difference spectra, it was found that on the (100)-step CO preferentially occupies bridge sites, whereas on the (111)-step site, adsorption at top sites was found.
3.2. $\mathrm{OH}$ adsorption on stepped $\mathrm{Pt}(111)$ surfaces.

Adsorbed $\mathrm{OH}$ is very important for $\mathrm{CO}$ oxidation, since the oxidation mechanism takes place according to a Langmuir-Hinshelwood mechanism. For that reason, $\mathrm{OH}$ adsorption was also studied on the (111) plane and on stepped surfaces (Table 1-Table 3). On the (111) terraces, adsorption of $\mathrm{OH}$ at top and fcc sites has similar energies, whereas it was not possible to obtain a stable configuration for the other two types of surface sites (i.e. hcp-hollow and bridge).

In both cases $\mathrm{OH}$ adsorbs on a bridge-position (see Fig. 4) between two Pt atoms of the step-edge (A1 site), the nature of the step causing the adsorption energies being roughly $0.3-0.4 \mathrm{eV}$ higher for the (100)-step compared to the (111)-step. Also, there is a large increase in the adsorption energies of $\sim 0.5 \mathrm{eV}$ for the (111)-step and $\sim 0.8 \mathrm{eV}$ for the (100)-step compared to the planar Pt(111) surface.

These results have to be compared to the $\mathrm{CV}$ measurements obtained for the stepped surfaces (see Fig. 3). For $\mathrm{Pt}(111)$ electrodes, the onset for $\mathrm{OH}$ adsorption is $0.6 \mathrm{~V}$ in perchloric acid solutions. For the stepped surfaces with (111)-steps, there is not a clear indication where the adsorption of $\mathrm{OH}$ on the step takes place, since it probably occurs in the region where $\mathrm{H}$ adsorption on the terrace takes place. This latter signal is large and for that reason, masks the small contribution from $\mathrm{OH}$ adsorption on the step. However, on the $\operatorname{Pt}(110)$ surface, which can be also considered as the stepped surface $\mathrm{Pt}[2(111) \times(111)], \mathrm{OH}$ adsorption takes place at ca. $0.2 \mathrm{~V}$, as indicated by the $\mathrm{CO}$ displacement technique [40], in good agreement with the difference in adsorption energy found here. For the adsorption on the (100)-step, the major problem is that the step adsorption is a competitive process, in which the $\mathrm{H}$ adsorption process is coupled with the $\mathrm{OH}$ desorption and vice versa. For that reason, the onset potential depends on the energy of adsorption on the step of both hydrogen and $\mathrm{OH}$, not allowing for a direct comparison to the present calculations.

\section{3. $\mathrm{CO}$ and $\mathrm{OH}$ co-adsorption on the stepped $\mathrm{Pt}(111)$} surfaces

Afterwards investigating the independent adsorption of $\mathrm{CO}$ and $\mathrm{OH}$, we finally studied the co-adsorption of both species on both types of steps. The results are summarized in Table 4-Table 5. The most stable configurations are shown in Fig. 5. As can be seen, significant differences are observed between both step-edges and with the previous results obtained for each species adsorbing separately. First of all, on both steps the calculated energy for the most stable configurations is $0.1 \mathrm{eV}$ [for (111)-steps] and $0.4 \mathrm{eV}$ [for (100)-steps] lower than the sum of the energies of the most stable configurations for $\mathrm{CO}$ and $\mathrm{OH}$ separately, indicating certain repulsion between the co-adsorbates. Secondly, the most stable configuration (i.e. the preferred binding sites) for the co-adsorbed $\mathrm{CO}+\mathrm{OH}$ system changes as well. These differences are a consequence of the modification of the local 
electronic structure of the neighboring atoms when $\mathrm{CO}$ or $\mathrm{OH}$ are co-adsorbed. Thus, for the surfaces with (100)-steps CO prefers the F2 site (fcc adsorption site on the $\mathrm{Pt}(111$ ) terrace), while $\mathrm{OH}$ adsorbs on the A1 site (bridge site along the step-edge).

On the other hand, the most stable combination for surfaces with (111)-steps has both $\mathrm{CO}$ and $\mathrm{OH}$ co-adsorbed at F-1 positions, with an overall binding energy of $4.77 \mathrm{eV}$. In this configuration both $\mathrm{CO}$ and $\mathrm{OH}$ are bonded to one $\mathrm{Pt}$ atom (Fig. 5) along the step-edge, As has been shown experimentally in Fig. 3, the potential for hydrogen adsorption/desorption on the step changes when $\mathrm{CO}$ is additionally present on the step, reflecting alterartions in the adsorption sites on the step neighboring the adsorbed CO. Thus, the presence of adsorbed $\mathrm{CO}$ (or $\mathrm{OH}$ ) modifies the adsorption energy of the adjacent surface sites.

From the results presented here, none of the adsorption processes clearly predominates. For the stepped surfaces with (100)-steps, $\mathrm{OH}$ remains on the same adsorption site (A1) but $\mathrm{CO}$ can be adsorbed at different positions (e.g. A1, A3, H2 and $\mathrm{T} 2$ ) without changing the overall binding energy of the $\mathrm{CO} / \mathrm{OH}$ system: $4.9-5.0 \mathrm{eV}$.

Concerning the surfaces with (111)-steps, the opposite situation is found, since the most stable adsorption site for a single $\mathrm{CO}$ is kept (F-1), while $\mathrm{OH}$ can be adsorbed either on the $\mathrm{A} 1$ or $\mathrm{F}-1$ position with again similar binding energies for the $\mathrm{CO}+\mathrm{OH}$ systems: 4.77 and $4.74 \mathrm{eV}$, respectively

The different behavior of the two stepped surfaces for the co-adsorption of $\mathrm{CO}+\mathrm{OH}$ necessarily implies a different reactivity. For the reaction between $\mathrm{OH}$ and $\mathrm{CO}$, significant differences have been found experimentally, both in acid and alkaline media. In acid media, where it has been proposed that the mobility of $\mathrm{CO}$ is very high, the rate constant for $\mathrm{CO}$ oxidation in the presence of (111)-steps is always higher than in the presence of (100)-steps [64]. This implies that the presence of the (111)-steps is more effective in the electrocatalytic $\mathrm{CO}$ oxidation process. These results are in agreement with the studies presented here. First of all, the adsorption of $\mathrm{OH}$ on the steps is always energetically more favorable than the adsorption on the terrace, and for that reason, the $\mathrm{CO}$ oxidation process is catalyzed by the presence of steps. Regarding the differences between the reactivity of the two steps, $\mathrm{CO}$ and $\mathrm{OH}$ are on neighboring sites in the most stable configuration for the surfaces having (111)-steps, so that the reaction between the two species is facilitated. Also, the next stable combination involves the $\mathrm{CO}$ on the F-1 position, while $\mathrm{OH}$ is adsorbed on the A1 position. As already mentioned, this combination has a binding energy of $4.74 \mathrm{eV}$. Note that this was expected to be the most stable combination according to the reported single adsorption energies of the $\mathrm{CO}$ and $\mathrm{OH}$ species (see Tab. 3).

On the other hand, in the most stable configuration $\mathrm{CO}$ and $\mathrm{OH}$ are at distant positions when (100)-steps are present on the surface, so that a direct reaction is not feasible. For the reaction to take place on the surface with (100)-steps, either $\mathrm{CO}$ or $\mathrm{OH}$ should diffuse over the surface to neighboring sites, which implies reaching a less stable configuration. In fact, the following most stable combinations are also involving the $\mathrm{OH}$ species adsorbed on the A1 position, while $\mathrm{CO}$ is adsorbed on the A3 (bridge-site on the terrace), H2 (hcp site on the terrace) and T2 (atop site on the $\mathrm{Pt}(111)$ terrace) positions with binding energies of $4.99,4.95$ and $4.94 \mathrm{eV}$, respectively. From all these combinations the one in which $\mathrm{CO}$ and $\mathrm{OH}$ are closest each other corresponds to the one where the $\mathrm{CO}$ is adsorbed on the T2 position. The binding energy of this structure is 4.94 $\mathrm{eV}$. Thus, from all the other possible combinations with energies close to the most stable configuration, in only one of them $\mathrm{CO}$ and $\mathrm{OH}$ are close to react. Further, diffusion of $\mathrm{CO}$ is always energetically more favorable than the diffusion of $\mathrm{OH}$, since in all the very stable configurations, $\mathrm{OH}$ is adsorbed atop of the step-edge. Also, when $\mathrm{CO}$ is diffusing over the surface, the energetically most favorable configurations always implies a $\mathrm{CO}$ close to the adsorbed $\mathrm{OH}$ for surface with (111)-steps, whereas with (100)-steps three out of four configurations imply a $\mathrm{CO}$ molecule far from the $\mathrm{OH}$ species. Hence, both our reported theoretical and experimental data suggests that surfaces containing (111)-steps are expected to be more reactive towards CO oxidation than surfaces containing (100)-steps.

\section{Summary and Outlook}

The adsorption energies of $\mathrm{CO}, \mathrm{OH}$, and $\mathrm{CO}+\mathrm{OH}$ on planar $\operatorname{Pt}(111)$ and vicinal surfaces containing (111)- or (100)-steps have been evaluated by means of DFT. Our results show that the binding for the co-adsorption of $\mathrm{CO}$ and $\mathrm{OH}$ on the (100)-steps is stronger than in the presence of (111)-steps. For $\mathrm{OH}$ adsorption, the difference in adsorption energy between (111) terrace sites and steps are in agreement with that found in electrochemical environments with voltammetry. In the case of $\mathrm{CO}$, the experimental assignation of the adsorption geometry for $\mathrm{CO}$ adsorbed on the step site is corroborated by the DFT calculations. The highest adsorption energy for the co-adsorbance of $\mathrm{CO}$ and $\mathrm{OH}$ on the (100)-step is $5.02 \mathrm{eV}$, while the most likely reactive configuration has a slightly lower binding energy of $4.94 \mathrm{eV}$. In the latter structure the $\mathrm{OH}$ is on the bridge site of the stepedge, while $\mathrm{CO}$ occupies the $\mathrm{T} 2$-site, which corresponds to an atop position close to the step-edge (where $\mathrm{OH}$ is adsorbed). For the case of (111)-steps binding energies are lower. Here, the most stable configuration is where both reactants are located at fcc sites (F-1) in front of (but underneath) the step-edge, having an overall binding energy of $4.77 \mathrm{eV}$. These results are in agreement with the experimental data, in which a different behavior of the (111) and (100)-steps for CO adsorption and oxidation has been found. Also, the adsorption geometries of $\mathrm{CO}$ on the step sites,

\section{Acknowledgements}

This work has been supported by the European Union through the Marie-Curie-ITN ELCAT. J.B., A.C.-V. and T.J. gratefully acknowledge support from the "Deutsche 
Published: Physical Chemistry Chemical Physics. 2013, 15: 18671-18677. doi:10.1039/C3CP53282H

Forschungsgemeinschaft” (DFG) as well as by the bwGRiD acknowledge the support from MICIN (project No. for computing resources. Further, support from the European CTQ2010-16271)

Resarch Council through the ERC-StG THEOFUN is gratefully acknowledged. E.H and C. B.-R. also 
Published: Physical Chemistry Chemical Physics. 2013, 15: 18671-18677.

doi:10.1039/C3CP53282H

\section{Figures}
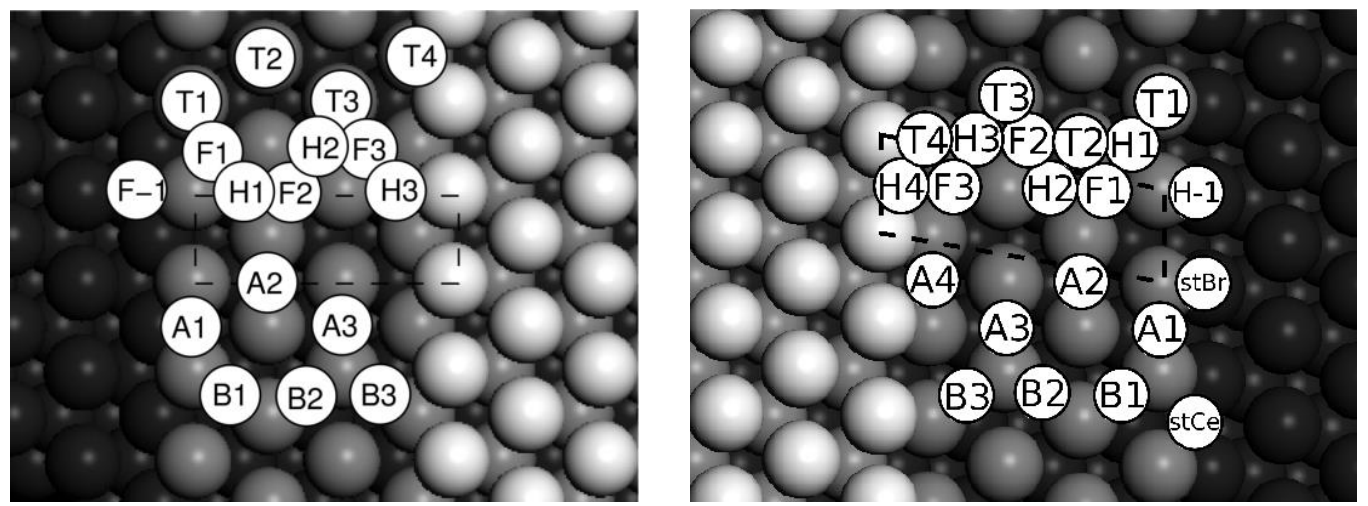

Figure 1: Hard-sphere models of the $\mathrm{Pt}(221)$ (left) and $\mathrm{Pt}(533)$ (right) surface, which served as model systems to investigate adsorption on (111)- and (100)-steps, respectively. The $(1 \times 1)$ surface unit cells are indicated by a dashed box, while all sites at which adsorption has been studied are labeled.
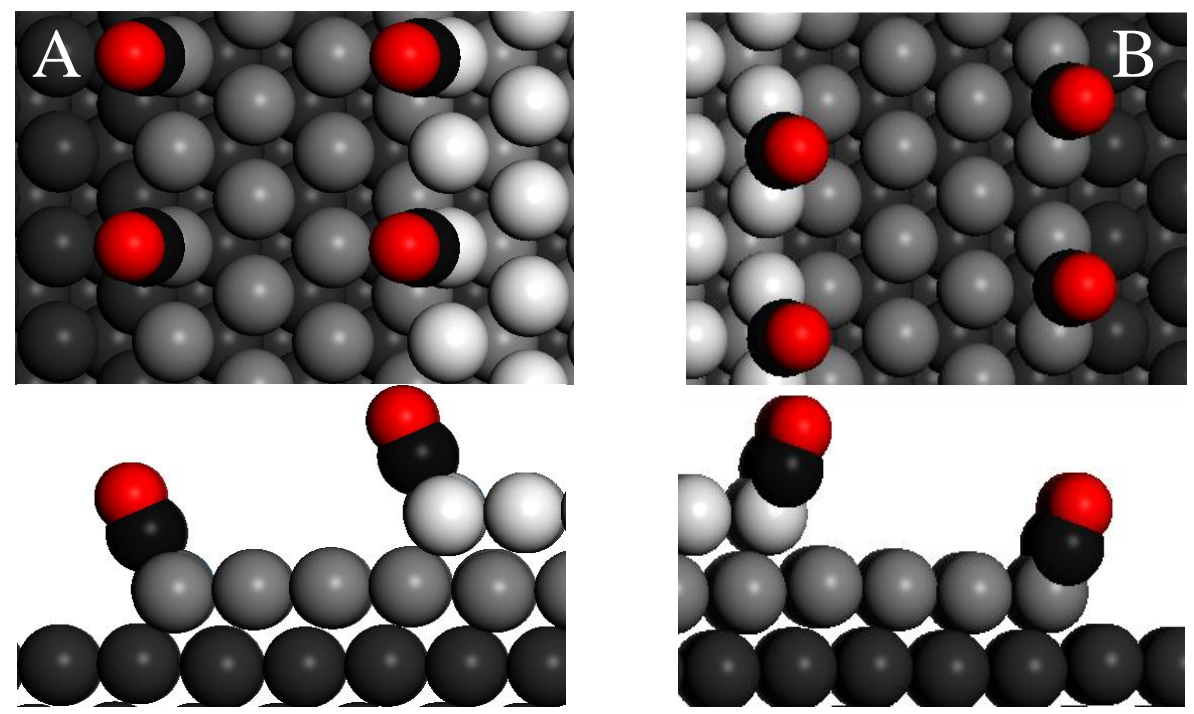

Figure 2: Optimized structure for $\mathrm{CO}$ adsorbed on the most stable adsorption site of $\operatorname{Pt}(221)$ (A) and $\operatorname{Pt}(533)$ (B). Top panels show the top view, while bottom panels are the corresponding side views.. 
Published: Physical Chemistry Chemical Physics. 2013, 15: 18671-18677. doi:10.1039/C3CP53282H
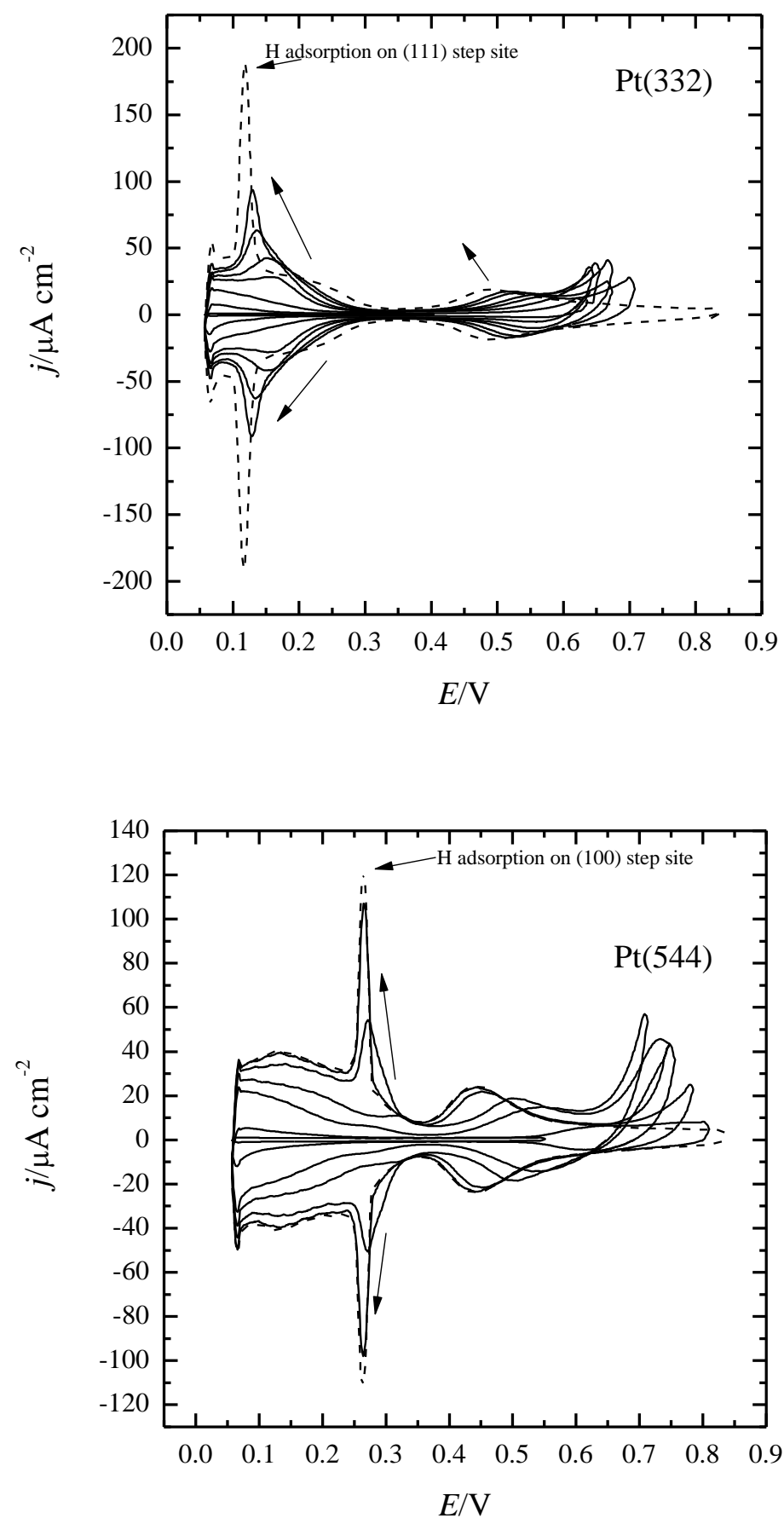

Figure 3. Partial CO stripping on the $\mathrm{Pt}(332)$ and $\mathrm{Pt}(544)$ electrodes in $0.5 \mathrm{M} \mathrm{H}_{2} \mathrm{SO}_{4}$. Potential values are with respect to the reversible hydrogen electrode (RHE). Arrows indicate the evolution of the voltammetric profile upon diminution of the $\mathrm{CO}$ coverage. The final voltammograms after complete removal of $\mathrm{CO}$ is shown in dashed lines. Only selected scans have been shown to improve clarity of the figure. 
Published: Physical Chemistry Chemical Physics. 2013, 15: 18671-18677.

doi:10.1039/C3CP53282H
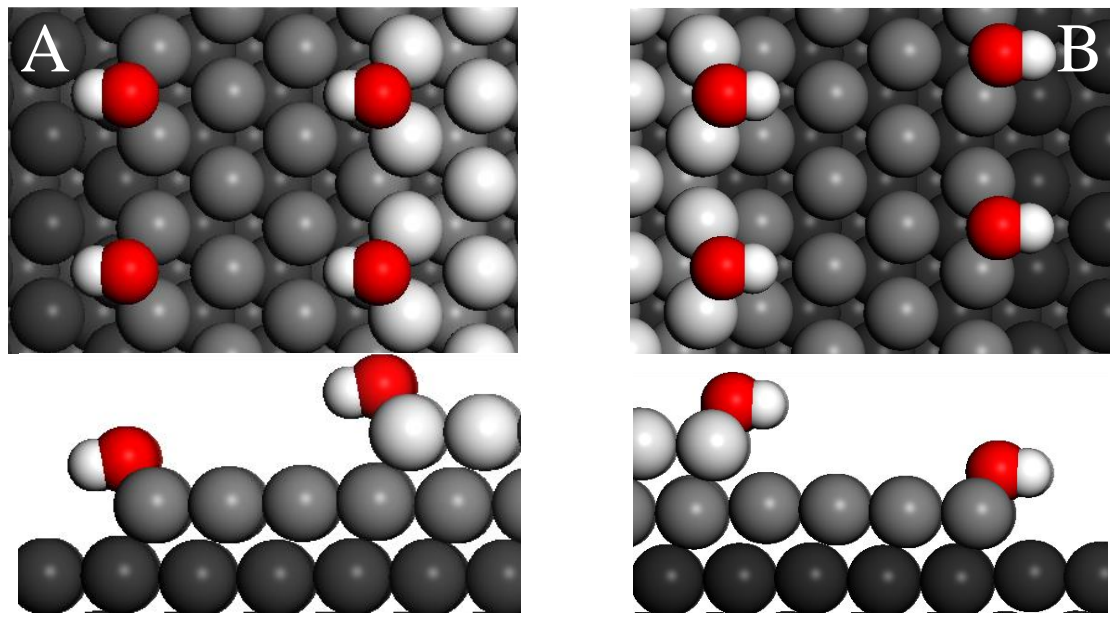

Figure 4: Optimized structure for $\mathrm{OH}$ adsorbed on the most stable adsorption site of $\operatorname{Pt}(221)$ (A) and $\operatorname{Pt}(533)$ (B). Top panels show the top view, while bottom panels are the corresponding side views.
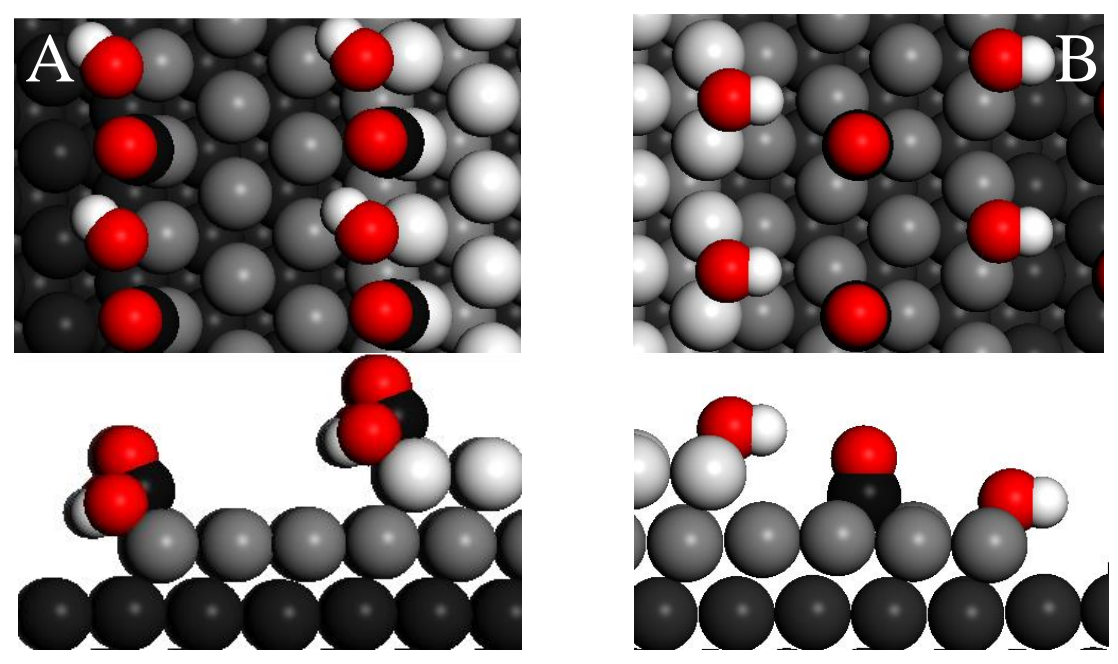

Figure 5: Optimized structure for co-adsorption of $\mathrm{CO}$ and $\mathrm{OH}$ in the most stable configurations on $\mathrm{Pt}(221)$ (A) and $\mathrm{Pt}(533)$ (B). Top panels show the top view, while bottom panels are the corresponding side views. 
Published: Physical Chemistry Chemical Physics. 2013, 15: 18671-18677. doi:10.1039/C3CP53282H

\section{Tables}

Table 1: Adsorption energies (in $\mathrm{eV}$ ) of $\mathrm{CO}$ and $\mathrm{OH}$ single adsorption on the (111) terrace.

\begin{tabular}{ccc}
\hline \hline Adsorption site & $E_{\text {bind }}^{\mathrm{OH}}[\mathrm{eV}]$ & $E_{\text {bind }}^{\mathrm{CO}} E[\mathrm{eV}]$ \\
\hline $2 \times 2$ top & 2.44 & 1.64 \\
$2 \times 2$ bridge & - & 1.68 \\
$2 \times 2 \mathrm{fcc}$ & 2.46 & 1.67 \\
$2 \times 2 \mathrm{hcp}$ & - & 1.66 \\
\hline \hline
\end{tabular}

Table 2: Adsorption energies (in $\mathrm{eV}$ ) of $\mathrm{CO}$ and $\mathrm{OH}$ single adsorption on the (100)-step, i.e. $\operatorname{Pt}(533)$ vicinal surface.

\begin{tabular}{ccc}
\hline \hline Adsorption site & $E_{\text {bind }}^{\mathrm{OH}}[\mathrm{eV}]$ & $E_{\text {bind }}^{\mathrm{CO}}[\mathrm{eV}]$ \\
\hline $\mathrm{A} 1$ & 3.29 & 2.11 \\
$\mathrm{~A} 2$ & 2.45 & 1.62 \\
$\mathrm{~A} 3$ & 2.46 & 1.68 \\
$\mathrm{~A} 4$ & - & -1.79 \\
$\mathrm{~B} 1$ & - & 1.58 \\
$\mathrm{~B} 2$ & - & 1.67 \\
$\mathrm{~B} 3$ & - & 1.52 \\
$\mathrm{~F} 1$ & - & 1.59 \\
$\mathrm{~F} 2$ & - & 1.69 \\
$\mathrm{~F} 3$ & - & 1.46 \\
$\mathrm{H} 1$ & - & - \\
$\mathrm{H}-1$ & 2.74 & 1.97 \\
$\mathrm{H} 2$ & - & 1.63 \\
$\mathrm{H} 3$ & 1.44 & 1.58 \\
$\mathrm{H} 4$ & - & -1.79 \\
$\mathrm{~T} 1$ & 2.75 & 2.00 \\
$\mathrm{~T} 2$ & 2.37 & 1.61 \\
$\mathrm{~T} 3$ & 2.40 & 1.62 \\
$\mathrm{~T} 4$ & 2.30 & 1.79 \\
\hline \hline
\end{tabular}


Published: Physical Chemistry Chemical Physics. 2013, 15: 18671-18677. doi:10.1039/C3CP53282H

Table 3: Adsorption energies (in $\mathrm{eV}$ ) of $\mathrm{CO}$ and $\mathrm{OH}$ single adsorption on different positions on the (111)-step, i.e. $\mathrm{Pt}(221)$ vicinal surface.

\begin{tabular}{ccc}
\hline \hline Adsorption site & $E_{\text {bind }}^{\mathrm{OH}}[\mathrm{eV}]$ & $E_{\text {bind }}^{\mathrm{CO}}[\mathrm{eV}]$ \\
\hline $\mathrm{A} 1$ & 2.92 & 1.94 \\
$\mathrm{~A} 2$ & 1.15 & 1.63 \\
$\mathrm{~A} 3$ & 2.35 & 1.62 \\
$\mathrm{~A} 4$ & - & - \\
$\mathrm{B} 1$ & - & - \\
$\mathrm{B} 2$ & 2.30 & 1.66 \\
$\mathrm{~B} 3$ & - & - \\
$\mathrm{F} 1$ & - & - \\
$\mathrm{F}-1$ & 2.74 & 2.02 \\
$\mathrm{~F} 2$ & - & - \\
$\mathrm{F} 3$ & - & 1.93 \\
$\mathrm{H} 1$ & - & - \\
$\mathrm{H} 2$ & - & 1.61 \\
$\mathrm{H} 3$ & - & - \\
$\mathrm{T} 1$ & 2.79 & - \\
$\mathrm{T} 2$ & 2.35 & 1.57 \\
$\mathrm{~T} 3$ & 2.39 & 1.53 \\
T4 & - & - \\
\hline \hline
\end{tabular}

Table 4: Adsorption energies (in eV) of $\mathrm{CO}+\mathrm{OH}$ coadsorbed on different positions on the (100)-step, i.e. $\mathrm{Pt}(533)$ vicinal surface.

\begin{tabular}{ccc}
\hline \hline CO site & OH site & $E_{\text {bind }}^{\mathrm{CO}+\mathrm{OH}}[\mathrm{eV}]$ \\
\hline $\mathrm{A} 1$ & $\mathrm{~A} 1$ & 4.9 \\
$\mathrm{~A} 1$ & $\mathrm{~A} 2$ & 4.62 \\
$\mathrm{~A} 1$ & $\mathrm{~A} 3$ & 4.6 \\
$\mathrm{~A} 1$ & $\mathrm{~T} 2$ & 4.55 \\
$\mathrm{~A} 1$ & $\mathrm{~T} 3$ & 4.54 \\
$\mathrm{~A} 1$ & $\mathrm{~T} 4$ & 4.66 \\
$\mathrm{~A} 3$ & $\mathrm{~A} 1$ & 4.99 \\
$\mathrm{~F} 2$ & $\mathrm{~A} 1$ & 5.02 \\
$\mathrm{H} 2$ & $\mathrm{~A} 1$ & 4.95 \\
$\mathrm{~T} 1$ & $\mathrm{~A} 1$ & 4.61 \\
$\mathrm{~T} 2$ & $\mathrm{~A} 1$ & 4.94 \\
$\mathrm{~T} 3$ & $\mathrm{~A} 1$ & 4.88 \\
$\mathrm{~T} 4$ & $\mathrm{~A} 1$ & 4.79 \\
\hline \hline
\end{tabular}


Published: Physical Chemistry Chemical Physics. 2013, 15: 18671-18677. doi:10.1039/C3CP53282H

Table 5: Adsorption energies (in eV) of $\mathrm{CO}+\mathrm{OH}$ coadsorbed on different positions on the (111)-step, i.e. $\operatorname{Pt}(221)$ vicinal surface.

\begin{tabular}{ccc}
\hline \hline CO site & OH site & $E_{\text {bind }}^{\mathrm{CO}+\mathrm{OH}}[\mathrm{eV}]$ \\
\hline F-1 & F-1 & 4.77 \\
F-1 & A2a & - \\
F-1 & A2b & 4.30 \\
F-1 & A3 & 4.37 \\
F-1 & T2 & 4.46 \\
F-1 & T3 & 4.42 \\
F-1 & T4 & 4.40 \\
A3 & A1 & 4.62 \\
F2 & A1 & - \\
H2 & A1 & - \\
F-1 & A1 & 4.74 \\
T2 & A1 & 4.51 \\
T3 & A1 & 4.41 \\
\hline \hline
\end{tabular}


Published: Physical Chemistry Chemical Physics. 2013, 15: 18671-18677.

doi:10.1039/C3CP53282H

\section{References}

D. J. Tarnowski, C. Korzeniewski, J. Phys. Chem. B, 101 (1997) 253.

2 F. Colmati, G. Tremiliosi, E. R. Gonzalez, A. Berna, E. Herrero, J. M. Feliu, Phys. Chem. Chem. Phys., 11 (2009) 9114.

3 J. Souza-Garcia, E. Herrero, J. M. Feliu, Chem. Phys. Chem., 11 (2010) 1391.

M. D. Maciá, E. Herrero, J. M. Feliu, Electrochim. Acta, 47 (2002) 3653.

V. Grozovski, V. Climent, E. Herrero, J. M. Feliu, Phys. Chem. Chem. Phys., 12 (2010) 8822.

R. Parsons, T. Vandernoot, J. Electroanal. Chem., 257 (1988) 9.

W. Gao, J. E. Mueller, Q. Jiang, T. Jacob, Angew. Chem. Int. Ed., 51 (2012) 9448.

B. Love, J. Lipkowski, ACS Symp. Ser., 378 (1988) 484.

L. Palaikis, D. Zurawski, M. Hourani, A. Wieckowski, Surf. Sci., 199 (1988) 183.

10 M. Bergelin, E. Herrero, J. M. Feliu, M. Wasberg, J. Electroanal. Chem., 467 (1999) 74.

11 N. P. Lebedeva, M. T. M. Koper, J. M. Feliu, R. A. van Santen, J. Electroanal. Chem., 524 (2002) 242.

12 E. Santos, E. P. M. Leiva, W. Vielstich, Electrochim. Acta, 36 (1991) 555.

13 N. M. Marković, T. J. Schmidt, B. N. Grgur, H. A. Gasteiger, R. J. Behm, P. N. Ross, J. Phys. Chem. B, 103 (1999) 8568.

14 E. Herrero, J. M. Feliu, S. Blais, Z. Radović-Hrapović, G. Jerkiewicz, Langmuir, 16 (2000) 4779.

15 E. Herrero, B. Alvarez, J. M. Feliu, S. Blais, Z. Radović-Hrapović, G. Jerkiewicz, J. Electroanal. Chem., 567 (2004) 139.

16 N. P. Lebedeva, M. T. M. Koper, J. M. Feliu, R. A. van Santen, J. Phys. Chem. B, 106 (2002) 12938.

17 B. Pozniak, Y. Mo, D. A. Scherson, Faraday Discuss., 121 (2002) 313.

18 N. P. Lebedeva, M. T. M. Koper, E. Herrero, J. M. Feliu, R. A. van Santen, J. Electroanal. Chem., 487 (2000) 37.

19 M. T. M. Koper, T. J. Schmidt, N. M. Marković, P. N. Ross, J. Phys. Chem. B, 105 (2001) 8381.

20 C. A. Angelucci, F. C. Nart, E. Herrero, J. M. Feliu, Electrochem. Commun., 9 (2007) 1113.

21 C. A. Angelucci, E. Herrero, J. M. Feliu, J. Solid State Electrochem., 11 (2007) 1531.

22 P. Strasser, M. Eiswirth, G. Ertl, J. Chem. Phys., 107 (1997) 991.

23 A. V. Petukhov, W. Akemann, K. A. Friedrich, U. Stimming, Surf. Sci., 402 (1998) 182.

24 S. Desai, M. Neurock, Electrochim. Acta. 48 (2003) 3759.

25 M. J. Janik, M. Neurock, Electrochim. Acta. 52 (2007) 5517.

26 M. J. Janik, C. Taylor, M. Neurock, Top. Catal. 46 (2007) 306.

27 G. Garcia, M. T. M. Koper, Phys. Chem. Chem. Phys., 10 (2008) 3802.

28 G. Garcia, M. T. M. Koper, Phys. Chem. Chem. Phys., 11 (2009) 11437.

29 G. Garcia, M. T. M. Koper, J. Am. Chem. Soc., 131 (2009) 5384.

30 M. van der Niet, O. T. Berg, L. B. F. Juurlink, M. T. M. Koper, J. Phys. Chem. C, 114 (2010) 18953.

31 M. van der Niet, A. den Dunnen, L. B. F. Juurlink, M. T. M. Koper, J. Chem. Phys., 132 (2010).

32 M. van der Niet, A. den Dunnen, L. B. F. Juurlink, M. T. M. Koper, Phys. Chem. Chem. Phys., 13 (2011) 1629.

33 M. van der Niet, A. den Dunnen, M. T. M. Koper, L. B. F. Juurlink, Phys. Rev. Lett., 107 (2011).

34 C. Verdozzi, P. A. Schultz, R. Q. Wu, A. H. Edwards, N. Kioussis, Phys. Rev. B 66 (2002) 125408.

35 V. Grozovski, V. Climent, E. Herrero, J. M. Feliu, Phys. Chem. Chem. Phys., 12 (2010) 8822.

36 J. Clavilier, D. Armand, S. G. Sun, M. Petit, J. Electroanal. Chem., 205 (1986) 267.

37 E. Herrero, J. M. Orts, A. Aldaz, J. M. Feliu, Surf. Sci., 440 (1999) 259.

38 K. B. Besocke, B. Krahl-Urban, H. Wagner, Surf. Sci., 68 (1977) 39.

39 S. Trasatti, Electrochim. Acta, 36 (1991) 1659.

40 R. Gómez, V. Climent, J. M. Feliu, M. J. Weaver, J. Phys. Chem. B, 104 (2000) 597.

41 P. J. Feibelman, B. Hammer, J. K. Nørskov, F. Wagner, M. Scheffler, R. Stumpf, R. Watwe, J. Dumesic, J. Phys. Chem. B 105 (2001) 4018.

42 D. Geschke, T. Baştuğ, T. Jacob, S. Fritzsche, W.-D. Sepp, B. Fricke, S. Varga, J. Anton, Phys. Rev. B, 64 (2001) 235411.

43 P. H. T. Philipsen, E. van Lenthe, J. G. Snijders, E. J. Baerends, Phys. Rev. B 56 (1997), 13556.

44 Q. M. Hu, K. Reuter, M. Scheffler, Phys. Rev. Lett. 98 (2007), 4.

45 F. Abild-Pedersen, M. P. Andersson, Surf. Sci. 601 (2007) 1747.

46 P. Lazić, M. Alaei, N. Atodiresei, V. Caciuc, R. Brako, S. Blugel, Physical Review B. 81 (2010) 6.

47 K. Doll, Surf. Sci. 573 (2004) 464.

48 I. Grinberg, Y. Yourdshahyan, A.M. Rappé, J. Chem. Phys. 117 (2002) 2264. 
Published: Physical Chemistry Chemical Physics. 2013, 15: 18671-18677.

doi:10.1039/C3CP53282H

49 S. E. Mason, I. Grinberg, A. M. Rappé, Physical Review B. 69 (2004) 161401.

50 E. D. German, M. Sheintuch, J. Phys. Chem. C. 112 (2008) 14377.

51 A. Stroppa, G. Kresse, New J. Phys. 10 (2008) 17

52 W. Liu, Y. F. Zhu, J. S. Lian, Q. Jiang, J. Phys. Chem. C. 111 (2007) 1005.

53 I. Dabo, A. Wieckowski, N. Marzari, Journal of the American Chemical Society. 129 (2007) 11045.

54 M. W. Severson, C. Stuhlmann, I. Villegas, M. J. Weaver, J. Chem. Phys., 103 (1995) 9832.

55 M. Mamatkulov, J. S. Filhol, Phys. Chem. Chem. Phys. 13 (2011) 7675.

56 P. Deshlahra, E. E. Wolf, W. F. Schneider, J. Phys. Chem. A. 113 (2009) 4125.

57 A.Y. Lozovoi, A. Alavi, J. Electroanal. Chem. 607 (2007) 140.

58 B. Hammer, O. H. Nielsen, J. K. Nørskov, Catalysis Letters. 46 (1997) 31.

59 H. Orita, N. Itoh, Y. Inada, Surf. Sci. 571 (2004) 161.

60 H. Orita, Y. Inada, The Journal of Physical Chemistry B. 109 (2005) 22469.

61 E. Herrero, V. Climent, J. M. Feliu, Electrochem. Commun., 2 (2000) 636.

62 Q. S. Chen, A. Berna, V. Climent, S. G. Sun, J. M. Feliu, Phys. Chem. Chem. Phys., 12 (2010) 11407.

63 M.J S. Farias, E. Herrero, J.M. Feliu, J. Phys. Chem. C, 117 (2013) 2903.

64 Q. S. Chen, J. M. Feliu, A. Berna, V. Climent, S. G. Sun, Electrochim. Acta, 56 (2011) 5993. 